\title{
Acute viral hepatitis B: laboratory reports $1980-4$
}

\author{
SHEILA POLAKOFF
}

Reports of patients with acute clinical hepatitis B have been received from laboratories in England, Wales, and Ireland since 1972. All available evidence suggests that since 1975 these reports include most of the cases of acute hepatitis B infection, in England at least. ${ }^{1.3}$

The annual number of reports, which was about 1000 in each of the years 1975 to 1979 , increased during the next five year period to more than 1200 in 1981, 1982, and 1983, with a sharp rise to almost 2000 in 1984 (table I).

TABLE I-Acute viral hepatitis B: laboratory reports $1980-4$

\begin{tabular}{lcccccc}
\hline & 1980 & 1981 & 1982 & 1983 & 1984 & Total \\
\hline Men & 715 & 888 & 895 & 902 & 1400 & 4800 \\
Women $^{274}$ & 320 & 340 & 326 & 580 & 1840 \\
\hline Total $^{\star}$ & 1004 & 1217 & 1244 & 1236 & 1995 & 6696
\end{tabular}

*Includes patients for whom sex was not stated.

Note-The large increase in the number of reports in 1984 was not sustained in 1985, when the total number of patients was similar and the percentage of patients with a history of drug abuse was the same.

The age and sex distributions of the patients, which varied little from year to year, remained similar to those found in the previous five years - that is, almost three quarters of the patients were men and, among patients of both sexes, about three quarters were young adults. Acute clinical hepatitis B remained uncommon among children and the elderly.

Based on these reports, the incidence of hepatitis B infections in adults aged 15-64 years was 6 per 100000 for men and 2 per 100000 for women. Compared with the corresponding rates in 1975-9, the incidence for men increased by $50 \%$, but the rate for women remained the same.

Thirty four deaths were reported: hepatitis was the cause in 30 . Among adults aged 15-64 case fatality rates were higher for women $(0.6 \%)$ than for men $(0.3 \%)$. The lowest rate $(0.3 \%)$ was found in patients aged $15-34$ years; there was an increase of $1 \cdot 2 \%$ in patients aged $35-64$ years, and $2 \cdot 0 \%$ at 65 or more years. There were two deaths among the 72 children.

\section{Relevant histories}

The hepatitis report form includes specific inquiries about health service occupation and recent history of drug abuse, bleeding disorders, transfusions, tattooing, patients in institutions for the mentally handicapped or renal units, injections, dentistry, surgery, travel abroad, or contact with cases or carriers. The histories reported are not necessarily causally associated. Of the 6696 reports, $62 \%$ included details of one or more of these histories.

As in 1975-9, drug abuse was the most common history. The increase in the annual total of patients in 1981 and again in 1984 was directly associated with an increase in the number of patients with a history of drug abuse (table II). Of the 1566 patients with a history of drug abuse reported during the five years, only $319(20 \%)$ were women.

\footnotetext{
Hepatitis Epidemiology Unit, Central Public Health Laboratory, London NW9

SHEILA POLAKOFF, MFCM, MD, consultant epidemiologist
}

TABLE II-Patients with acute hepatitis $B$ with a history of drug abuse as a percentage of total cases $1980-4$

\begin{tabular}{lllllll}
\hline & 1980 & 1981 & 1982 & 1983 & 1984 & Total \\
\hline Drug abusers as \% total cases & $17 \cdot 8$ & $22 \cdot 2$ & $20 \cdot 7$ & 22.9 & 30.4 & $23 \cdot 9$ \\
\hline
\end{tabular}

Male homosexuals formed $8 \%$ of all patients during the period (table III). From 1982 there was a sustained increase in this number, so that by 1984 there were twice as many as in 1980 .

TABLE III-History of patients

\begin{tabular}{lrr}
\hline & \multicolumn{2}{c}{ Patients } \\
\cline { 2 - 3 } History & \multicolumn{1}{c}{ No } & $\%$ \\
\hline Drug abuse & 1597 & $23 \cdot 9$ \\
Male homosexual & 520 & $7 \cdot 8$ \\
Contact with case or carriert & 626 & $9 \cdot 3$ \\
Bleeding disorder & 31 & $0 \cdot 5$ \\
Transfusion & 82 & $1 \cdot 2$ \\
Tattoo & 91 & $1 \cdot 4$ \\
Patient in institution for the mentally handicapped & 55 & $0 \cdot 8$ \\
Health service staff & 361 & $5 \cdot 4$ \\
Surgery, dentistry, or injection & 208 & $3 \cdot 1$ \\
Abroad (without any of histories specified above) & 640 & $9 \cdot 6$ \\
Total with history or relevant occupation & 4180 & $62 \cdot 4$ \\
Total reports & 6696 & \\
\hline
\end{tabular}

* 31 male homosexuals who were also drug abusers were included in both groups.

tExcludes health service staff and drug abusers or male homosexuals with a history of contact.

Drug abusers, male homosexuals, and health service staff were excluded from the 626 patients with a history of contact with a case or carrier, who formed $9 \%$ of the total. Of these exposures, 366 $(59 \%)$ were heterosexual, $63(10 \%)$ were household, and the remainder were other or not specified. Some of the household exposures may have been sexual because the relationship between patient and contact was often unspecified. Most of the patients with a history of heterosexual contact with cases or carriers were women, but $116(32 \%)$ were men.

Most of the infections were sporadic, but 11 patients were infected in two outbreaks associated with surgery. These are reported in the accompanying paper ( $p 33$ ).

The endemic pattern of hepatitis B infection in many institutions for the mentally handicapped was similar to that in 1975-9. The infections of 55 patients and 43 staff were usually sporadic and were associated with carriers rather than other acute infections. There were no reports of outbreaks in renal units.

\section{Acute hepatitis B infection in health service staff}

During the five years 364 cases of acute clinical hepatitis B in health service staff were reported, considerably more than the total of 287 reported in 1975-9. In 1980-4, however, 80 (22\%) acquired the infection while working abroad, whereas only $9 \%$ had done so in 1975-9.

Although specific immunoglobulin continued to be available throughout the period, most of the infected health service staff had either failed to report or were unaware of their exposure. Thirteen $(0 \cdot 8 \%)$ of the infections occurred despite prophylaxis. There were only two reports of infections in staff working in renal units, both of whom were physicians. One had taken repeated blood samples from 
TABLE IV—Acute hepatitis B among health service staff ${ }^{\star}$ (England only)

\begin{tabular}{|c|c|c|c|c|c|c|}
\hline \multirow[b]{2}{*}{ Staff category } & \multicolumn{3}{|c|}{$1975-9$} & \multicolumn{3}{|c|}{$1980-4$} \\
\hline & $\begin{array}{l}\text { Mid-period } \\
\text { number }\end{array}$ & $\begin{array}{l}\text { No of reported } \\
\text { cases of acute } \\
\text { hepatitis B }\end{array}$ & $\begin{array}{l}\text { Average annual } \\
\text { rate per } 100000\end{array}$ & $\begin{array}{l}\text { Mid-period } \\
\text { number }\end{array}$ & $\begin{array}{l}\text { No of reported } \\
\text { cases of acute } \\
\text { hepatitis B }\end{array}$ & $\begin{array}{l}\text { Average annual } \\
\text { rate per } 100000\end{array}$ \\
\hline Surgeons & 10372 & 6 & 12 & 11282 & 14 & 25 \\
\hline Physicians & 43828 & 27 & 12 & 47900 & 26 & 11 \\
\hline \multicolumn{7}{|l|}{ Laboratory staff: } \\
\hline Medical & 2232 & 3 & 27 & 2490 & 2 & 16 \\
\hline Scientific & 14291 & 13 & 18 & 15339 & 28 & 37 \\
\hline Nursing staff & 391953 & 131 & 7 & 423841 & 95 & 4 \\
\hline Dentists & 14354 & 12 & 17 & 15337 & 13 & 17 \\
\hline Staff in institutions for mentally handicapped & 28000 & 43 & 31 & $39163 t$ & 52 & 27 \\
\hline
\end{tabular}

* Staff who acquired the infection while working abroad were excluded from both five year periods. tFigures supplied by the Department of Health and Social Security. The 1980-4 mid-period number includes staff in small community units, who are not included in
1975-9.

a patient who had undergone a transplant operation who was a known highly infective carrier, but she could not recall any accidental inoculation or contamination. The other worked in a unit in which there were no carrier patients; the time of the onset suggested that the infection had been acquired before beginning work in the unit. None of the infections in health service staff were fatal.

Table IV shows the average annual incidence of hepatitis B estimated for the various staff groups. The denominators are derived from Health and Personal Social Services Statistics for England $1982 .{ }^{4}$ Actual numbers of staff were used when available; otherwise whole time equivalents were used. Since data for Wales and Ireland are presented differently, rates were estimated for England only.

The rates for staff of institutions for the mentally handicapped during the two periods are not comparable as the number of staff in 1980-4 was considerably increased by staff in small community units, who were not included in the figures for 1975-9. The rate for nurses decreased from 7 per 100000 in $1975-9$ to 4 per 100000 in
1980-4. There was little or no difference between the rates for physicians and dentists. The rates for surgeons and laboratory scientific staff were twice as high as those found in 1975-9.

Although the increased incidence during 1980-4 in two groups is a cause for concern, the annual average numbers of infections, on which these rates were based, were small-for example, three surgeons, six laboratory staff. Nevertheless, these infections should be prevented by active immunisation of staff at high risk.

\section{References}

1 Polakoff S, Tillett $\mathrm{H}$. Routine laboratory reports of patients with acute hepatitis B as indicators of incidence of the disease. Fournal of Infection 1984;8:44-8.

Public Health Laboratory Service Collaborative Report. Acute hepatitis B associated with gynaecological surgery. Lancet 1980;i:1-6.

Polakoff S, Tillett H. Acute viral hepatitis B: laboratory reports 1975-79. Br Med f 1982;284: 1881-2.

4 Department of Health and Social Security. Health and Personal Social Services Statistics for England. London: HMSO, 1982.

(Accepted 27 March 1986)

\title{
Lesson of the Week
}

\section{Resolution of dyskinesia and the "on-off" phenomenon in thyrotoxic patients with Parkinson's disease after antithyroid treatment}

\author{
T H CARADOC-DAVIES
}

Many patients with Parkinson's disease develop complications of long term treatment with compounds containing levodopa. These complications include the "on-off" phenomenon and dyskinesia and develop after two or three years of treatment in some $15-40 \%$ of patients. ${ }^{1}$ Thyrotoxicosis has been reported in association with Parkinson's disease in patients with severe tremor, and in three cases the tremor subsided with treatment of the endocrine disorder. ${ }^{2}$ I report two patients who developed late side effects of treatment of Parkinson's disease which were reversed by correcting co-existing thyrotoxicosis and examine the postulated mechanism.

Department of Medicine, University of Otago, Dunedin, New Zealand T H CARADOC-DAVIES, FRACP, senior lecturer

\section{Symptoms and signs of thyrotoxicosis may easily be dismissed as late complications of levodopa in patients receiving this drug for Parkinson's disease; only a high index of suspicion and a therapeutic trial of antithyroid medication will yield the correct diagnosis}

\section{Case 1}

A 66 year old woman with a seven year history of Parkinson's disease well controlled for four years with levodopa-carbidopa (Sinemet) presented with a four month history of night terrors, depression, dyskinetic movements, and episodes of freezing typical of the "on-off" phenomenon. She admitted 